\title{
Licochalcone $D$ induces apoptosis and inhibits migration and invasion in human melanoma A375 cells
}

\author{
LINGLING SI $^{*}$, XINYAN YAN ${ }^{3 *}$, WENJIN HAO $^{1}$, XIAOYI MA $^{2}$, HUANHUAN REN $^{2}$, \\ BOXUE REN $^{2}$, DEFANG LI ${ }^{1}$, ZHENGPING DONG $^{1}$ and QIUSHENG ZHENG ${ }^{1}$
}

\author{
${ }^{1}$ School of Integrated Traditional Chinese and Western Medicine, Binzhou Medical University, Yantai, Shandong 264000; \\ ${ }^{2}$ School of Pharmacy, Shihezi University, Key Laboratory of Xinjiang Endemic Phytomedicine Resources, \\ Ministry of Education, Shihezi, Xinjiang 832002; ${ }^{3}$ People's Hospital of Xinjiang Uygur Autonomous Region, \\ Uygur, Xinjiang 830001, P.R. China
}

Received January 11, 2017; Accepted March 16, 2018

DOI: 10.3892/or.2018.6329

\begin{abstract}
The aim of the present study was to determine the effects of Licochalcone D (LD) on the apoptosis and migration and invasion in human melanoma A375 cells. Cell proliferation was determined by sulforhodamine B assay. Apoptosis was assessed by Hoechst 33258 and Annexin V-FITC/PI staining and JC-1 assay. Total intracellular reactive oxygen species (ROS) was examined by DCFH-DA. Wound healing and Transwell assays were used to detect migration and invasion of the cells. The activities of matrix metalloproteinase (MMP-2 and MMP-9) were assessed via gelatin zymography. Tumor growth in vivo was evaluated in C57BL/6 mice. RT-PCR, qPCR, ELISA and western blot analysis were utilized to measure the mRNA and protein levels. Our results showed that LD inhibited the proliferation of A375 and SK-MEL-5 cells in a concentration-dependent manner. After treatment with LD, A375 cells displayed obvious apoptotic characteristics, and the number of apoptotic cells was significantly increased. Pro-apoptotic protein Bax, caspase-9
\end{abstract}

Correspondence to: Professor Qiusheng Zheng, School of Integrated Traditional Chinese and Western Medicine, Binzhou Medical University, 346 Guanhai Road, Yantai, Shandong 264000, P.R. China

E-mail: zqsyt@sohu.com

*Contributed equally

Abbreviations: LD, Licochalcone D; SRB, sulforhodamine B; FITC, Annexin V-fluorescein isothiocyanate; PI, propidium iodide; RT-PCR, semi-quantitative reverse transcription-polymerase chain reaction; qPCR, quantitative real-time PCR methods; $\triangle \Psi \mathrm{m}$, mitochondrial membrane potential; JC-1, 5,5',6,6'-tetrachloro1,1',3,3'-tetraethyl benzimidazole carbocyanine iodide; ROS, reactive oxygen species; MMP-2, matrix metalloproteinase-2; MMP-9, matrix metalloproteinase-9; ELISA, enzyme-linked immunosorbent assay

Key words: Licochalcone D, A375 cells, apoptosis, migration, invasion, ROS and caspase- 3 were upregulated, while anti-apoptotic protein Bcl-2 was downregulated in the LD-treated cells. Meanwhile, LD induced the loss of mitochondrial membrane potential $(\Delta \Psi \mathrm{m})$ and increased the level of ROS. ROS production was inhibited by the co-treatment of LD and free radical scavenger $N$-acetyl-cysteine (NAC). Furthermore, LD also blocked A375 cell migration and invasion in vitro which was associated with the downregulation of MMP-9 and MMP-2. Finally, intragastric administration of LD suppressed tumor growth in the mouse xenograft model of murine melanoma $\mathrm{B} 16 \mathrm{~F} 0$ cells. These results suggest that $\mathrm{LD}$ may be a potential drug for human melanoma treatment by inhibiting proliferation, inducing apoptosis via the mitochondrial pathway and blocking cell migration and invasion.

\section{Introduction}

Malignant melanoma, accounting for the greater percentage of skin cancer cases is a highly lethal cutaneous tumor which has shown an increasing incidence in the last few decades (1). The conventional therapy for malignant melanoma includes surgery, chemotherapy, immunotherapy and radiation therapy (2). However, these therapeutic strategies are typically self-limited and far from satisfactory. The urgent task on hand is to seek an effective drug to improve the comprehensive treatment, reduce the side effects and reduce the mortality of melanoma.

It has been demonstrated that flavonoids have cytotoxic activities toward multiple types of human cancer cells, yet have little or no effect on normal cells. Numerous flavonoids in traditional Chinese herbs may be promising candidates for the development of novel anticancer drugs (3). Previously, we found that Licochalcone $\mathrm{C}$ induced apoptosis via $\mathrm{B}$-cell lymphoma 2 family proteins in T24 cells (4). Licochalcone A induced T24 bladder cancer cell apoptosis by increasing intracellular calcium levels (5). Isoliquiritigenin inhibited proliferation and induced apoptosis via alleviating hypoxia and reducing glycolysis in mouse melanoma B16F10 cells (6). Recently, we demonstrated that Licochalcone B arrested cell cycle progression and induced apoptosis in human breast cancer MCF-7 cells (7). Taken together, these studies 
indicate the application potential of flavonoids for cancer therapy. Licochalcone D (LD, Fig. 1) is a flavonoid compound mainly existing in the root of Glycyrrhiza inflata, commonly named Chinese licorice which possesses antioxidant and anti-inflammatory properties (8-10). However, the effect of LD on the metastasis and apoptosis of A375 cells has never been reported. The present study was designed to evaluate the anticancer, metastatic and apoptotic effects of LD on A375 cells in vitro.

\section{Materials and methods}

Cell culture and treatment. A375 cells were purchased from the Cell Bank of the Committee on Type Culture Collection of the Chinese Academy of Sciences (Shanghai, China). B16F0 cells were obtained from the China Center for Type Culture Collection (Wuhan, China). SK-MEL-5 cells were purchased from the American Type Culture Collection (ATCC; Manassas, VA, USA). A375 cells were cultured in Gibco ${ }^{\mathrm{TM}}$ DMEM, while SK-MEL-5 and B16F0 cells were cultured in Gibco ${ }^{\mathrm{TM}}$ RPMI-1640 (Thermo Fisher Scientific, Inc., Waltham, MA, USA) containing HyClone ${ }^{\mathrm{TM}} 10 \%$ fetal bovine serum (FBS; GE Healthcare Life Sciences), 2 mM L-glutamine, $100 \mathrm{U} / \mathrm{ml}$ penicillin and $100 \mu \mathrm{g} / \mathrm{ml}$ streptomycin. All cell lines were cultured at $37^{\circ} \mathrm{C}$ in $5 \% \mathrm{CO}_{2}$. Cells were allowed to attach for $24 \mathrm{~h}$ before treatment. LD was dissolved in dimethyl sulfoxide (DMSO) (Sigma-Aldrich; Merck KGaA, Darmstadt, Germany) and diluted with fresh medium to achieve the desired concentration. The final concentration of DMSO did not exceed $0.2 \%$ in the fresh medium, and DMSO at this concentration has no significant effect on cell viability.

Cell viability assay. A 375 cells were trypsinized and seeded into 96-well plates at $10^{5}$ cells/well. Thereafter, cells were exposed to $\operatorname{LD}(0,1,2.5,5,15,30,45,60,75$ and $90 \mu \mathrm{mol} / \mathrm{l})$ for $24 \mathrm{~h}$. SK-MEL-5 cells were trypsinized and seeded into 96-well plates at $10^{4}$ cells/well, and exposed to $\operatorname{LD}(0,20,40,60$ and $80 \mu \mathrm{mol} / \mathrm{l})$ for $24 \mathrm{~h}$, followed by extra incubation in fresh medium for another $24 \mathrm{~h}$. The effect of LD-induced cytotoxicity was evaluated using sulforhodamine B (SRB) (Tokyo Chemical Industry Co., Ltd., Tokoy, Japan) assay as previously described (6). The optical density was detected at a wavelength of $490 \mathrm{~nm}$.

Observation of morphological changes. A375 cells were trypsinized and seeded into 6 -well plates at $2 \times 10^{5}$ cells/well. After being treated with $\operatorname{LD}(0,30,60$ and $90 \mu \mathrm{mol} / \mathrm{l})$ for $24 \mathrm{~h}$, the cells were fixed with Carnoy's fixative consisting of methanol (Kaixin, Tianjin, China) and glacial acetic acid (3:1, v/v). Hoechst $33258(5 \mu \mathrm{g} / \mathrm{ml}$ ) (Solarbio, Beijing, China) was applied for visualization of the nucleus. The changes in nuclear morphology of apoptotic cells were observed by labeling the cells with the nuclear stain Hoechst 33258 and examining them under fluorescence microscopy at x200 magnification (MIC00266; Carl Zeiss, Oberkochen, Germany). Cells that exhibited reduced nuclear size, chromatin condensation, intense fluorescence, and nuclear fragmentation were considered as apoptotic.

Trypan blue exclusion test. The lethality of LD on A375 cells was determined by the trypan blue exclusion test as previously

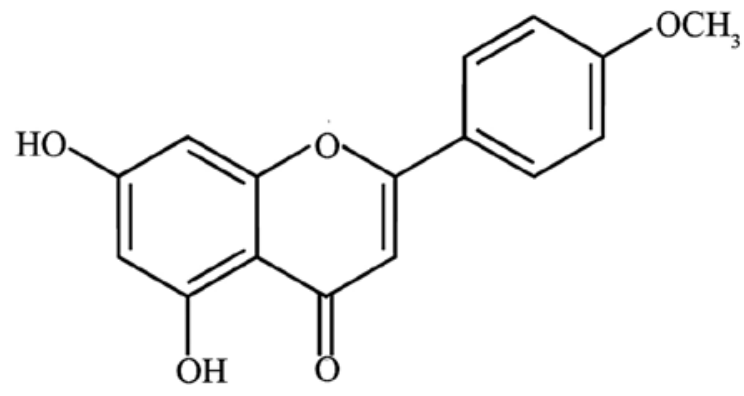

Figure 1. Chemical structure of Licochalcone D.

described (11). After $24 \mathrm{~h}$ of incubation with LD $(0,30,60$ and $90 \mu \mathrm{mol} / \mathrm{l}), \mathrm{A} 375$ cells were removed from the culture medium and cells that excluded trypan blue (Sigma-Aldrich; Merck KGaA) were counted in a Neubauer chamber.

Annexin V/PI staining assay. Annexin V-fluorescein isothiocyanate (FITC)/propidium iodide kit (BD Pharmingen, San Diego, CA, USA) was used to assess cell apoptosis according to the supplier's instructions (12). After treatment with LD $(0,30,60$ and $90 \mu \mathrm{mol} / \mathrm{l})$ for $24 \mathrm{~h}$, cells were collected, counted, centrifuged and resuspended in $500 \mu \mathrm{l}$ of $1 \mathrm{X}$ binding buffer. Then Annexin V-FITC (5 $\mu \mathrm{l})$ and PI (5 $\mu \mathrm{l})$ were added to each sample. The samples were incubated in the dark at room temperature for $15 \mathrm{~min}$ and examined immediately on a flow cytometer (BD Biosciences, Franklin Lakes, NJ, USA). The assays were repeated at least three times.

RNA isolation, RT-PCR and $q P C R$. Semi-quantitative reverse transcription-PCR (RT-PCR) (13) and quantitative real-time PCR (qPCR) (14) were performed to examine the mRNA expression of Bax, Bcl-2, caspase-3, caspase-9, MMP-2 and MMP-9. The primer sequences (synthesized by Sangon Biotech Co., Ltd., Shanghai, China) are shown in Table I. Total cellular RNA was extracted using TRIzol reagent (Sangon Biotechnology Co., Ltd.), and then cDNA was synthesized with the use of $3 \mu$ l total RNA primed with oligo(dT) (deoxy-thymidine) (Fermentas, Vilnius, Lithuania) in $25 \mu \mathrm{l}$ reaction solution. The resulting total cDNA was used in the polymerase chain reaction. The reaction conditions were established by $12.5 \mu 12 \mathrm{X}$ PCR Master (Tiangen Biotech, Beijing, China), $3 \mu \mathrm{l}$ cDNA template, and $0.5 \mu \mathrm{l}$ of each primer. RT-PCR products were resolved on a $1.5 \%$ agarose gel, stained with ethidium bromide, and the intensity was quantified by Gel-Pro analysis software (ImageJ software, version 1.49n; National Institutes of Health, Bethesda, MD, USA). qPCR amplification was conducted using SYBR-Green q-RT-PCR kit reagents (Fermentas) according to the manufacturer's instructions. The cycling conditions were as follows: $95^{\circ} \mathrm{C}$ for $5 \mathrm{~min}$, followed by 40 cycles of $95^{\circ} \mathrm{C}$ for $5 \mathrm{~min}$, Tm (C) for $30 \mathrm{sec}$, and $72^{\circ} \mathrm{C}$ for $30 \mathrm{sec}$. For quantification, the relative gene expression was calculated using $\mathrm{Ct}$ methods.

Detection of $\Delta \Psi m$ by $J C$ - 1 . A375 cells were incubated with LD $(0,30,60$ and $90 \mu \mathrm{mol} / \mathrm{l})$ for $24 \mathrm{~h}$, then washed with cold PBS, exposed to $500 \mu \mathrm{l} \mathrm{JC-1}$ dye solution (KeyGen Biotech. Inc., Nanjing, China) and incubated at $37^{\circ} \mathrm{C}$ for $20 \mathrm{~min}$ in 
Table I. Sequences of the primer pairs for real-time RT-PCR and qPCR.

\begin{tabular}{llc}
\hline Gene & \multicolumn{1}{c}{ Primer } & Size (bp) \\
\hline Bax & F: 5'-ACGAACTGGACAGTAACATGGAG-3' & 839 \\
& R: 5'-CAGTTTGCTGGCAAAGTAGAAAAG-3' & 6492 \\
Bcl-2 & F: 5'-ATGTGTGTGGAGAGCGTCAA-3' \\
& R: 5'-GAGACAGCCAGGAGAAATCAA-3' & \\
Caspase-3 & F: 5'-CTGGACTGTGGCATTGAGAC-3' & 2689 \\
& R: 5'-ACAAAGCGACTGGATGAACC-3' \\
Caspase-9 & F: 5'-AGGGTCGCTAATGCTGTTC-3' & 1848 \\
MMP-2 & R: 5'-GCAAGATAAGGCAGGGTGAG-3' \\
& F: 5'-ACCTACACCAAGAACTTCCG-3' & 3152 \\
MMP-9 & R: 5'-TTGGTTCTCCAGCTTCAGGT-3' \\
& F: 5'-TGACAGCGACAAGAAGTG-3' & 2387 \\
GAPDH & R: 5'-CAGTGAAGCGGTACATAGG-3' & 1513 \\
& F: 5'-CAAGGTCATCCATGACAACTTTG-3' & \\
& R: 5'-GTCCACCACCCTGTTGCTGTAG-3'
\end{tabular}

F, forward; R, reverse.

the dark. After washed three times with incubation buffer, the cells were diluted in $500 \mu 1$ incubation buffer and the fluorescence intensity of the cells was analyzed using a FACScan flow cytometer (BD Biosciences). The wavelength at excitation/emission $485 / 580 \mathrm{~nm}$ (red), and then at excitation/emission $485 / 530 \mathrm{~nm}$ (green) was read by a fluorescent plate reader (Varioskan Flash 3001; Thermo Fisher Scientific, Inc., Waltham, MA, USA).

Detection of intracellular ROS levels. ROS in A375 cells were detected using a fluorescent probe-2,7-dichlorofluorescein diacetate (DCFH-DA) (Sigma-Aldrich; Merck KGaA) as previously described (15). When DCFH-DA penetrates cells, it is hydrolyzed to DCFH by an esterase which is oxidized to fluorescent DCF by intracellular ROS. Thus, $2 \times 10^{5}$ cells/bottle were incubated with the indicated concentration of LD $(0,30,60$ and $90 \mu \mathrm{mol} / \mathrm{l})$ with or without ROS scavengers ( $N$-acetyl-cysteine; NAC) (Sigma-Aldrich; Merck KGaA) for $24 \mathrm{~h}$, then cells were incubated with DCFH-DA $(30 \mu \mathrm{mol} / \mathrm{l})$ at $37^{\circ} \mathrm{C}$ for $30 \mathrm{~min}$ and washed with PBS, and the fluorescence intensity of the cells was analyzed using a FACScan flow cytometry (BD Biosciences). In parallel, the wavelength at $495 \mathrm{~nm}$ excitation and $529 \mathrm{~nm}$ emission for DCF was read by a fluorescent plate reader (Varioskan Flash 3001; Thermo Fisher Scientific, Inc.).

Wound healing assays. A375 cells were trypsinized and seeded into 24-well plates at $10^{5}$ cells/well, and resuspended in serum-free DMEM with $0.1 \%$ DMSO (vehicle control). When the cells reached $90 \%$ confluence, the cells were wounded by scratching with a sterile pipette tip (16). The cells were treated with $\mathrm{LD}(0,1,2.5,5,15$ and $25 \mu \mathrm{mol} / 1)$ at $37^{\circ} \mathrm{C}$ with $5 \% \mathrm{CO}_{2}$ for $24 \mathrm{~h}$. Until normal (control) group healing, images of cell migration were captured at the indicated time (MIC00266; Carl Zeiss).
Assay for gelatin zymography. A375 cells were seeded in a 96-well $\left(10^{4}\right.$ cells/well) dish and stabilized in DMEM with $10 \% \mathrm{FBS}$ at $37^{\circ} \mathrm{C}$ for $24 \mathrm{~h}$. Then, the cells were treated with $\mathrm{LD}(0,5,15$ and $25 \mu \mathrm{mol} / \mathrm{l})$ for $24 \mathrm{~h}$. The conditioned medium was harvested and then concentrated by a Thermo centrifugal filter device (1,500 x g, $5 \mathrm{~min})$. The conditioned media with the same amount of protein were mixed with an equal volume of sodium dodecyl sulfate (SDS)-gel loading buffer without boiling and then subjected to $10 \%$ SDS polyacrylamide gels containing $0.1 \%$ gelatin under non-reducing conditions. After electrophoresis at $4^{\circ} \mathrm{C}$, the gels were soaked in zymogen renaturation buffer for $1 \mathrm{~h}$ to remove residual SDS and rinsed in distilled water. The gels were incubated in a developing buffer (50 mmol/l Tris- $\mathrm{HCl}, 150 \mathrm{mmol} / \mathrm{l} \mathrm{NaCl}, 5 \mathrm{mmol} / \mathrm{l} \mathrm{CaCl}{ }_{2}$, $\left.2 \mu \mathrm{mol} / 1 \mathrm{ZnCl}_{2}, \mathrm{pH} 7.5\right)$ for $18 \mathrm{~h}$, stained with $0.2 \%$ Coomassie blue R-250 (Beyotime Institute of Biotechnology, Haimen, China), and visualized by destaining solution (35\% methanol, $10 \%$ acetic acid). The gelatinase activities of MMP-2 and MMP-9 were determined by analyzing the signal intensity using Gel-PRO Analyzer (ImageJ software version 1.49n; National Institutes of Health) (17).

Assay of MMP-2 and MMP-9 activities. A375 cells ( $2 \times 10^{5}$ cells/bottle), in the log phase of proliferation, were incubated at $37^{\circ} \mathrm{C}$ with $5 \% \mathrm{CO}_{2}$. After treatment with $\mathrm{LD}(0,5$, 15 and $25 \mu \mathrm{mol} / 1$ ) for $24 \mathrm{~h}$, MMP-2 and MMP-9 activities were quantitatively measured by enzyme-linked immunosorbent assay (ELISA) (Shanghai Westang Bio-Tech Co., Shanghai, China) according to the manufacturer's instructions. In brief, $100 \mu \mathrm{l}$ of each sample was dispensed into a 96-well microtitre plate coated with polyclonal anti-MMP-2 or MMP-9 followed by $37^{\circ} \mathrm{C}$ for $40 \mathrm{~min}$. After washing, $50 \mu \mathrm{l}$ of detection reagent was applied into each well at $37^{\circ} \mathrm{C}$ for $30 \mathrm{~min}$. Chromogenic agent $\mathrm{A}$ and $\mathrm{B}(50 \mu \mathrm{l})$ were added and mixed for $30 \mathrm{sec}$ and then put at $37^{\circ} \mathrm{C}$ for $30 \mathrm{~min}$. Absorbance was read at $450 \mathrm{~nm}$ 

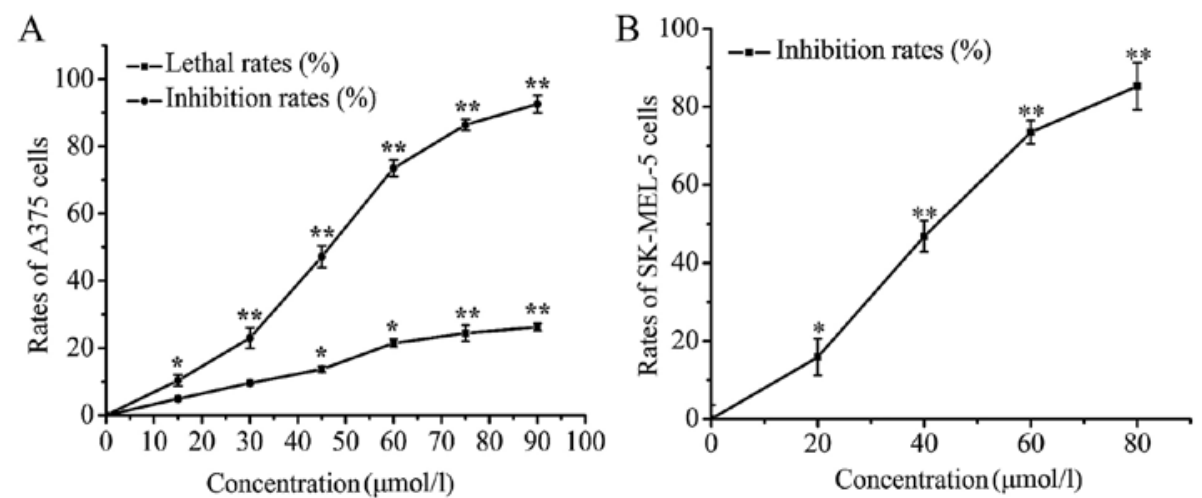

Figure 2. Effects of Licochalcone D (LD) on A375 and SK-MEL-5 cell proliferation and survival. (A) The inhibition rate of A375 cell proliferation was determined by SRB assay and the lethal rate was detected by trypan blue exclusion test after treatment with LD $(0,15,30,45,60,75$ and $90 \mu \mathrm{mol} / 1)$ for $24 \mathrm{~h}$. (B) SK-MEL-5 cell viability was determined by SRB assay after $24 \mathrm{~h}$ treatment with $\mathrm{LD}(0,20,40,60$ and $80 \mu \mathrm{mol} / \mathrm{l})$. Data are presented as means \pm SD of at least three independent experiments. ${ }^{*} \mathrm{P}<0.05,{ }^{* * *} \mathrm{P}<0.01$ compared with the untreated control group cells.

on a microplate reader (Varioskan Flash 3001; Thermo Fisher Scientific, Inc.).

Transwell assays. Transwell migration assays were performed to assess cancer cell migration upon treatments in Transwell chambers with a non-coated membrane using a 24-well insert (Corning, Inc., Corning, NY, USA). A375 cells $\left(10^{5}\right.$ cells/well $)$ were seeded in the top of the chambers and incubated overnight. For invasion assays, A375 cells were plated in the top chamber with a Matrigel-coated membrane. Medium (without serum) was added to the upper chamber. The medium (containing 10\% FBS) was added in the lower chamber. After $24 \mathrm{~h}$, the cells were fixed in $10 \%$ neutral buffered formalin solution for $30 \mathrm{~min}$ and stained with Giemsa. Cells on each insert were calculated using a light microscope (Axioskop; Carl Zeiss).

In vivo antitumor activity. All experimental protocols in the present study were performed after the approval by the Institutional Animal Care and Use Committee of Shihezi University. B16F0 cells $(200 \mu \mathrm{l})\left(10^{5}\right.$ cells $\left./ \mathrm{ml}\right)$ were injected subcutaneously into the right flank of C57BL/6 mice, and then tumor formation in the C57 mice was monitored. Subcutaneous tumors induced by B16F0 cells in C57 mice were randomly divided into three treatment groups (6 in each group). One week after inoculation, the mice were administered 25 and $50 \mathrm{mg} / \mathrm{kg}$ of LD by intragastric administration (i.g.) daily, respectively. Control mice received the same volume of normal saline. The mice were observed for body weight changes every two days. A week later after the first treatment with LD, the mice in each group were anesthetized with $3 \%$ sodium pentobarbital via intraperitoneal injection. The implanted melanomas were separated and weighed, and the tumor inhibition rate (TIR) was calculated according to the following formulate: $\operatorname{TIR}(\%)=(\mathrm{WC}-\mathrm{WE}) / \mathrm{WE} \times 100 \%$. WC is the mean tumor weight in the control group; WE is the mean tumor weight in the tested groups, respectively. More than $30 \%$ was regarded as having an inhibitory effect. Mice with signs of severe distress or pain were euthanized before the end of the study.

Statistical analysis. All values are expressed as the mean $\pm \mathrm{SD}$. All experiments were repeated at least three times. Statistical differences between two groups were determined using the Student's t-test. Two-way analysis of variance (ANOVA) with general linear model procedures using a univariate approach was applied for more than two groups. The results were considered significantly different at $\mathrm{P}<0.05$ and highly significantly different at $\mathrm{P}<0.01$.

\section{Results}

$L D$ treatment inhibits the proliferation of human melanoma cells. Cell viability in vitro was assessed using SRB assay to show the inhibitory effect of LD on cell proliferation. After treatment with $\operatorname{LD}(0,15,30,45,60,75$ and $90 \mu \mathrm{mol} / 1)$ for $24 \mathrm{~h}$, the inhibition rate of A375 cells increased with an increase in the concentration of $\mathrm{LD}$, and the $\mathrm{IC}_{50}$ value was $\sim 48.61 \mu \mathrm{mol} / 1$. LD $(<30 \mu \mathrm{mol} / 1)$ did not significantly affect the lethality rate of the A375 cells (Fig. 2A), which indicated that the inhibitory effect of LD on cell proliferation was not due to the direct killing of the A375 cells. In addition, the effect of LD on another human melanoma cell line SK-MEL- 5 also be examined. The SK-MEL-5 cells were treated with different concentrations $(20,40,60$ and $80 \mu \mathrm{mol} / \mathrm{l})$ of LD. The data from the cell viability assay indicated that LD inhibited the proliferation of SK-MEL-5 cells in a concentration-dependent manner (Fig. 2B).

$L D$ induces the apoptosis of A375 cells. We explored whether LD could induce apoptosis in A375 cells. After treatment with LD for $24 \mathrm{~h}$, a fewer number of cells and smaller circular morphology of the A375 cells were observed by microscopy (Fig. 3A). As shown in Fig. 3B, cells exhibited obvious apoptotic characteristics after treatment with LD $(0$, 30,60 and $90 \mu \mathrm{mol} / \mathrm{l}$ ) for $24 \mathrm{~h}$; nuclei were condensed and fragmented in the apoptotic cells. Moreover, we confirmed the ell apoptosis rate using an Annexin V-PI apoptosis detection kit, and the percentages of apoptotic cells were calculated. As shown in Fig. 3C and D, the cell apoptosis rates in the LD-treated cells $(0,30,60$ and $90 \mu \mathrm{mol} / \mathrm{l})$ were $1.94 \pm 4.39,11.26 \pm 2.35,31.65 \pm 5.60$ and $52.10 \pm 4.79 \%$, respectively. Clearly, with the increasing concentration of LD, the percentage of apoptotic cells also increased. As shown in Fig. 3E and F, LD downregulated the mRNA level of Bcl-2 
A

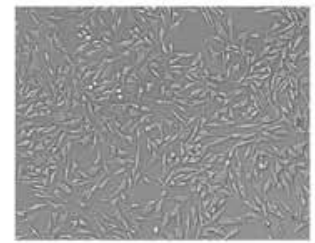

B

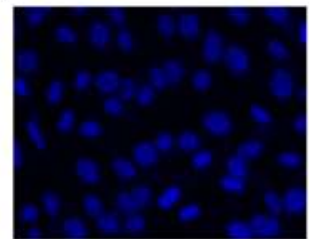

Control

C

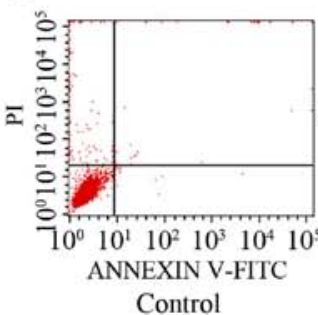

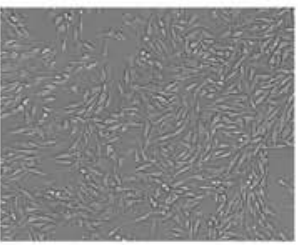

$30 \mu \mathrm{mol} / \mathrm{l}$

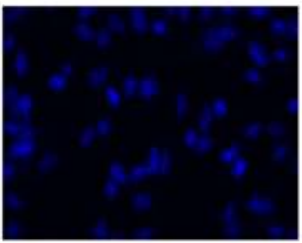

$30 \mu \mathrm{mol} / 1$
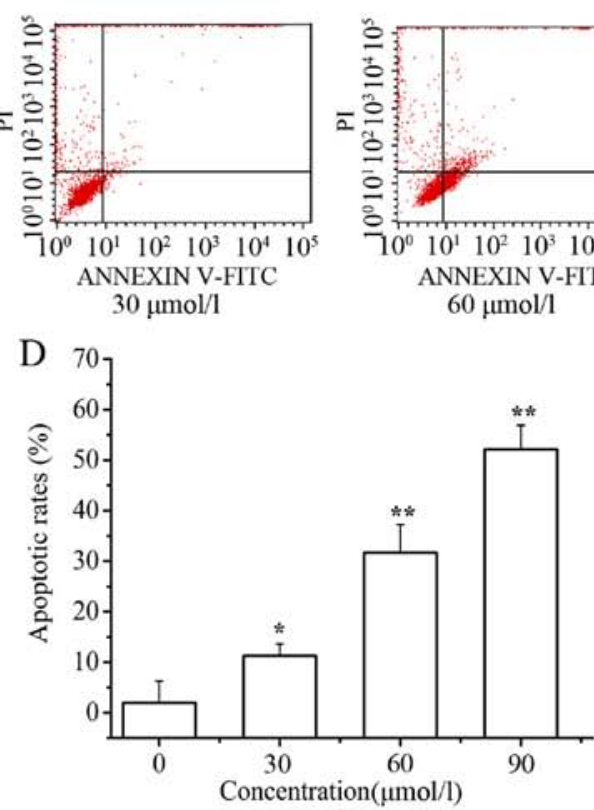

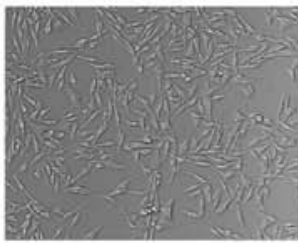

$60 \mu \mathrm{mol} / 1$

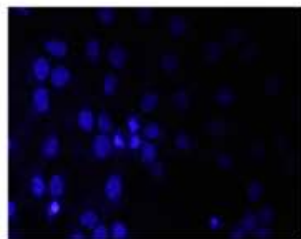

$60 \mu \mathrm{mol} / \mathrm{l}$

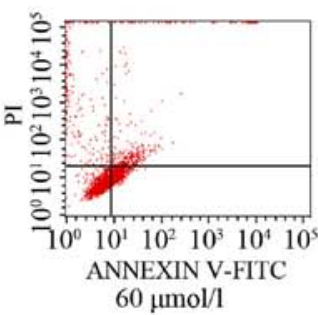

$60 \mu \mathrm{mol} / \mathrm{l}$

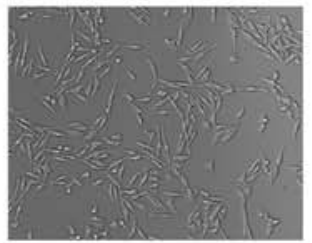

$90 \mu \mathrm{mol} / 1$

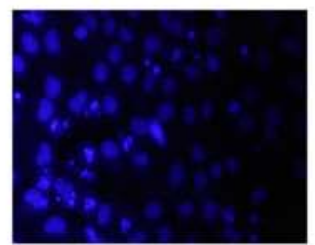

$90 \mu \mathrm{mol} / \mathrm{l}$

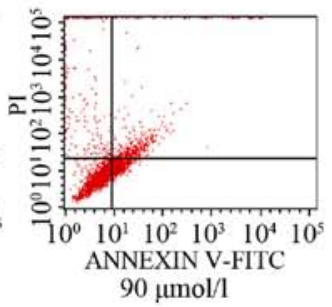

E
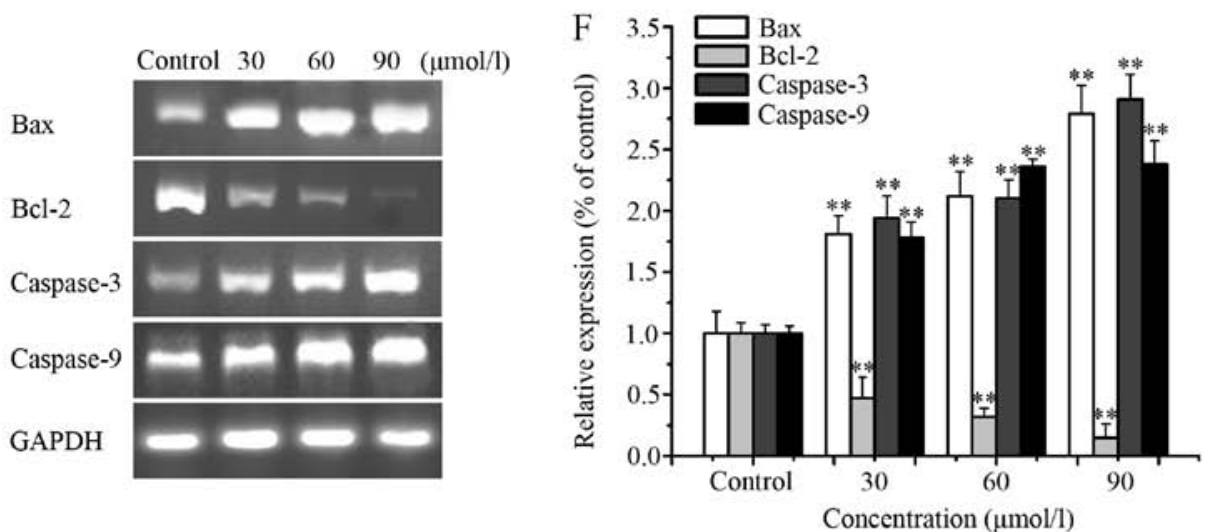

Figure 3. Induction of apoptosis in A375 cells by Licochalcone D (LD) treatment. (A) Cell morphological changes were observed by phase-contrast microscopy (magnification, x200) after treatment with $\operatorname{LD}(0,30,60$ and $90 \mu \mathrm{mol} / \mathrm{l})$ for $24 \mathrm{~h}$. (B) Apoptosis was visualized by the appropriate changes in nuclei stained with Hoechst 33258 (blue) (magnification, x200). (C) The effects of LD on the induction of A375 cell apoptosis were analyzed by FCM analysis. (D) The apoptosis rate as statistically analyzed. (E) RT-PCR analyses of A375 cells to evaluate mRNA expression of Bcl-2, Bax, caspase-3 and caspase-9. (F) qPCR analyses of A375 cells to evaluate mRNA expression of Bcl-2, Bax, caspase-3 and caspase-9, and relative intensities were normalized by levels of GAPDH. The untreated group level was considered as ' 1.0 '. Data are presented as means $\pm \mathrm{SD}$ of at least three independent experiments. ${ }^{*} \mathrm{P}<0.05,{ }^{* *} \mathrm{P}<0.01$ as compared with the untreated control group.

and upregulated the mRNA levels of caspase-3, caspase- 9 and Bax.
Effects of LD on $\triangle \Psi m$ and ROS in A375 cells. (Fig. 4A and B) The changes in mitochondrial membrane potential $\Delta \Psi \mathrm{m}$ in 

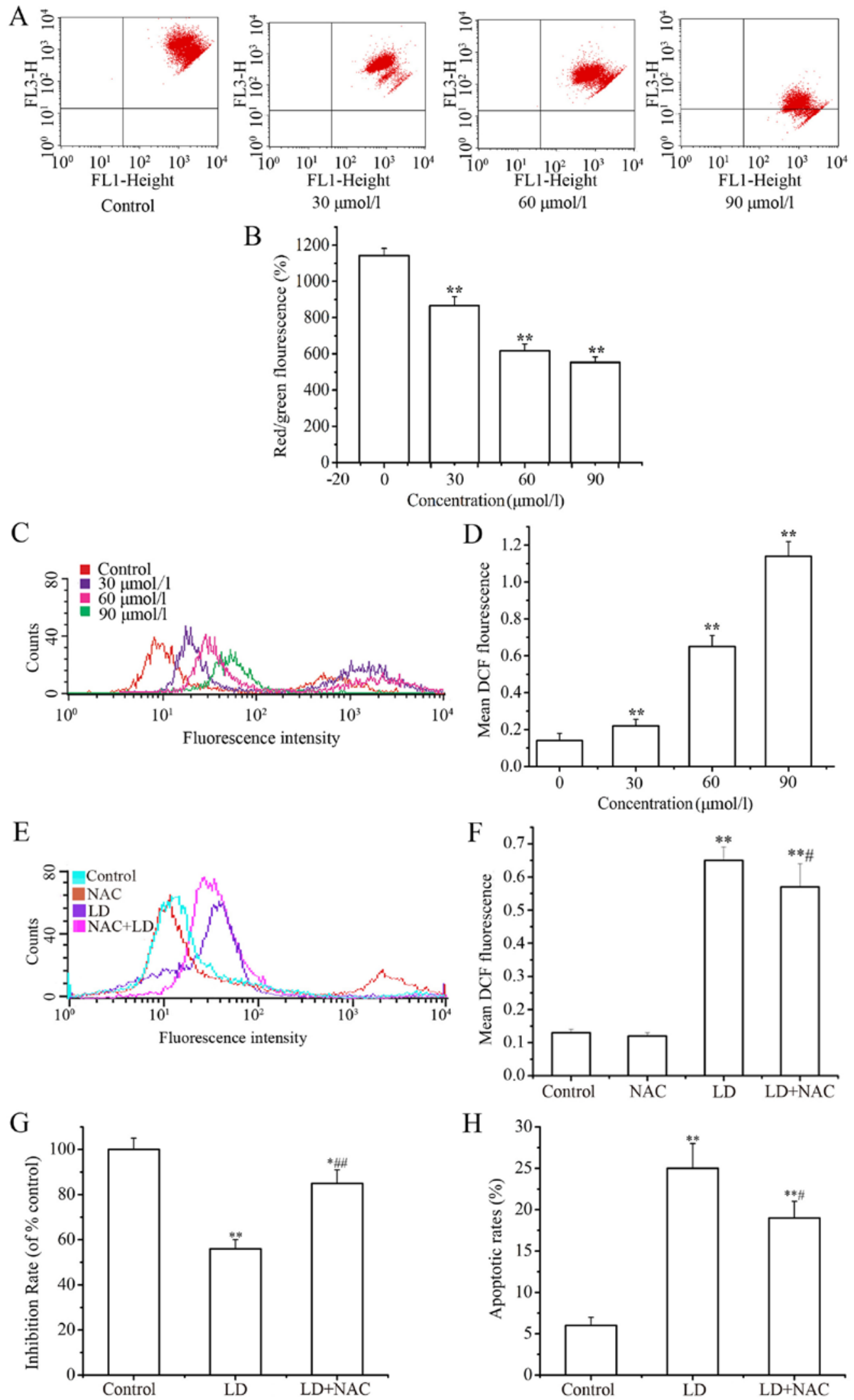

Figure 4. Licochalcone D (LD) treatment decreases the mitochondrial membrane potential and increases ROS production in A375 cells. (A and B) Cells were treated with $\mathrm{LD}(0,30,60$ and $90 \mu \mathrm{mol} / \mathrm{l})$ and then exposed to JC-1 dye solution. Changes in mitochondrial membrane potential $\Delta \Psi \mathrm{m}$ in A375 cells were tested by staining with JC-1 dye solution after treatment with LD, and the staining was detected by flow cytometry and fluorescence plate reader. A concentration-dependent reduction in $\triangle \Psi \mathrm{m}$ was observed in the LD-treated cells. (C and D) DCF-DA was used as a fluorescence indicator to measure the intracellular ROS level. The ROS levels in the LD-treated cells were significantly higher than that noted in the control. Moreover, ROS scavenger (NAC) was used to determine whether ROS exerted an interference effect against LD-induced A375 cell proliferation. (E and F) ROS production was inhibited obviously with the co-addition of NAC $(300 \mu \mathrm{M})$. (G) A375 cell survival after a $24 \mathrm{~h}$ post-NAC treatment. (H) Effects of NAC on apoptotic rates in A375 cells. All data are presented as the means $\pm \mathrm{SD}$ of at least three independent experiments; ${ }^{*} \mathrm{P}<0.05,{ }^{* *} \mathrm{P}<0.01$ as compared with the normal control group. ${ }^{\#} \mathrm{P}<0.05$ as compared with the LD alone treated group. NAC, $N$-acetyl-cysteine. 

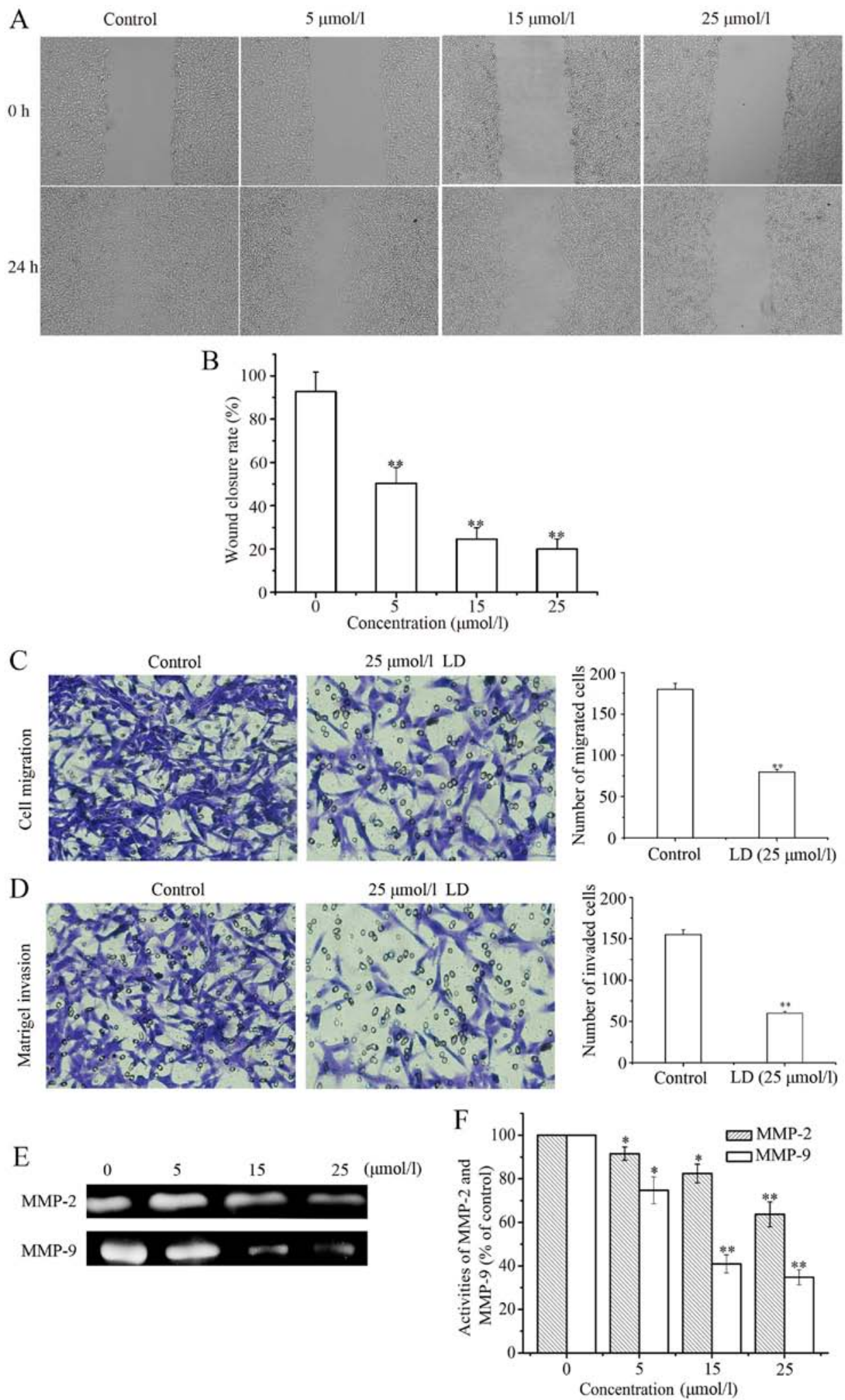

Figure 5. Licochalcone D (LD) decreases A375 cell migration and invasion. (A) Representative images of the wound-healing assay in A375 cells following treatment with $\mathrm{LD}(0,5,15,25 \mu \mathrm{mol} / \mathrm{l})$ for $24 \mathrm{~h}$ under a x200 light microscope (Carl Zeiss). (B) Analysis of the wound closure rate. (C) Transwell migration assay of A375 cells upon treatment of $25 \mu \mathrm{mol} / 1 \mathrm{LD}$. (D) Transwell invasion assay of A375 cells upon treatment of $25 \mu \mathrm{mol} / 1$ LD. (E) Activities of MMP-2 and MMP-9 were determined via gelatin zymography. (F) The gray value in the same area for each band was measured by Gel-PRO Analyzer software, and the MMP-2 and MMP-9 activities were expressed as a percentage of the control. All data are presented as the means \pm SD of at least three independent experiments; ${ }^{*} \mathrm{P}<0.05,{ }^{* *} \mathrm{P}<0.01$ as compared with the normal control group.

A375 cells were tested by staining with JC-1 dye solution after treatment with $\mathrm{LD}$, and the staining was detected by flow cytometry and fluorescence plate reader. A decrease in the intensity of JC-1 dye solution staining reflects loss of the $\Delta \Psi \mathrm{m}$. A concentration-dependent reduction in $\Delta \Psi \mathrm{m}$ was observed in the LD-treated cells. (Fig. 4C and D) DCF-DA was used 

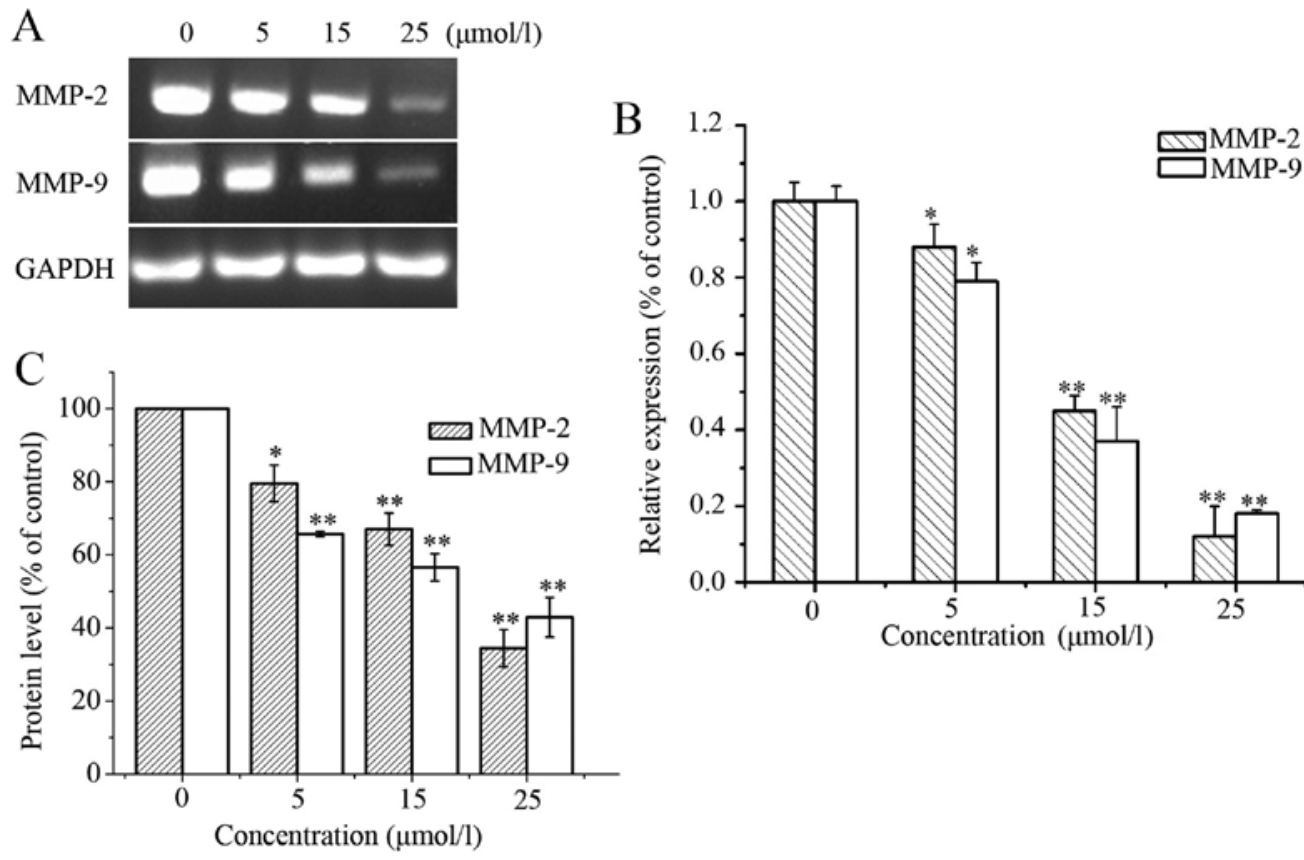

Figure 6. Levels of mRNA and protein expression of MMP-2 and MMP-9 in A375 cells treated with Licochalcone D (LD). Transcript levels for MMP-2 and MMP-9 were monitored by (A) quantitative real-time PCR and (B) RT-PCR analysis, and relative intensities were normalized by levels of GAPDH. (C) Protein levels of MMP-2 and MMP-9 were monitored by ELISA analysis. Data are presented as the means \pm SD of at least three independent experiments. "P<0.05, ${ }^{* *} \mathrm{P}<0.01$ as compared with the untreated control group.

as a fluorescence indicator to measure the intracellular ROS level. The ROS levels in the LD-treated cells were significantly higher than that noted in the control. (Fig. 4E and F) Moreover, ROS scavengers (NAC) were used to determine whether ROS exerted an interference effect against LD-induced A375 cell proliferation. ROS production was inhibited obviously with the co-addition of NAC $(300 \mu \mathrm{M})$. Meanwhile, the cell proliferation inhibition ratio increased (Fig. 4G) and the percentage of apoptotic cells decreased (Fig. $4 \mathrm{H}$ ) in the NAC co-treatment groups.

$L D$ decreases the migration and invasion ability of the A375 cells. After treatment with $\mathrm{LD}(0,5,15$ and $25 \mu \mathrm{mol} / \mathrm{l})$ for $24 \mathrm{~h}$, we assessed the effect of LD on A375 cell migration. As shown in Fig. 5A, wound healing was observable with a low magnification objective (200x) after $24 \mathrm{~h}$ wounding with a pipette tip. The wound closure rate was $92.67 \pm 9.08 \%$ in the absence of LD. However, the closure rates were $50.31 \pm 7.39 \%(\mathrm{P}<0.01)$, $24.53 \pm 5.32 \%(\mathrm{P}<0.01)$ and $20 \pm 4.55 \%(\mathrm{P}<0.01)$ after treatment with $\mathrm{LD}$, which indicated that the healing rate significantly decreased in a concentration-dependent manner (Fig. 5B). Next we performed Transwell assays to investigate whether LD affects the invasion and migration of A375 cells. The results showed that LD significantly suppressed cell migration in the A375 cells (Fig. 5C). Similar results were observed with cell invasion (Fig. 5D). Taken together, LD inhibited cell motility and invasiveness in vitro. The activities of MMP-2 and MMP-9 in conditioned media were determined via gelatin zymography assay. As shown in Fig. 5E and F, after treatment with LD for $24 \mathrm{~h}$, the activities of MMP-2 and MMP-9 were significantly decreased in a concentration-dependent manner. In order to evaluate the effect of LD on the mRNA expression of MMP-2 and MMP-9, validated mRNA target genes were evaluated with

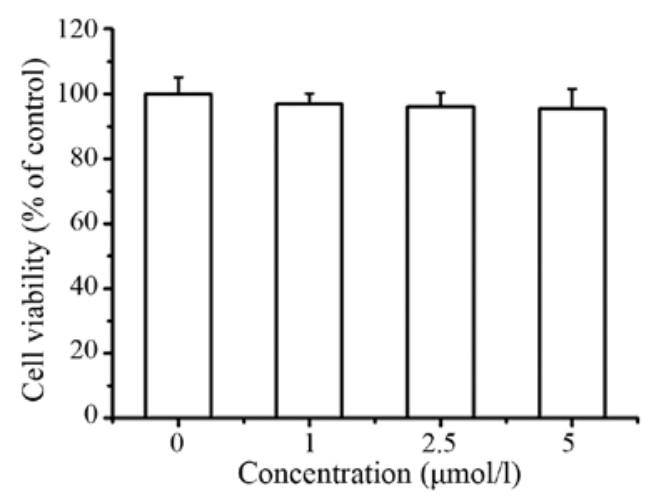

Figure 7. Effects of low concentrations of Licochalcone D (LD) on A375 cell proliferation. The inhibition rate on A375 cell proliferation was determined by SRB assay after cells were treated with low concentrations of LD $(1,2.5$ and $5 \mu \mathrm{mol} / \mathrm{l})$. Data are presented as means $\pm \mathrm{SD}$ of at least three independent experiments.

the RT-PCR and qPCR methods. Compared with the untreated group, LD treatment downregulated the mRNA expression of MMP-2 and MMP-9 (Fig. 6A and B). Similar to the mRNA expression, the protein levels of MMP-2 and MMP-9 also decreased in the LD-treated cells (Fig. 6C). In order to exclude the possibility of cell motility leading to the decrease in expression and secretion of MMPs, we measured the effect of LD at lower concentrations $(1,2.5$ and $5 \mu \mathrm{mol} / 1)$ on A375 cell migration. Lower concentrations of LD significantly decreased the wound healing rate (Fig. 8A and B). In addition, LD at lower concentrations $(1,2.5$ and $5 \mu \mathrm{mol} / \mathrm{l})$ had no apparent effect on the proliferation of A375 cells (Fig. 7). These results implied that LD treatment inhibited the migration of melanoma cells which was associated with downregulation of MMP-2 and MMP-9. 

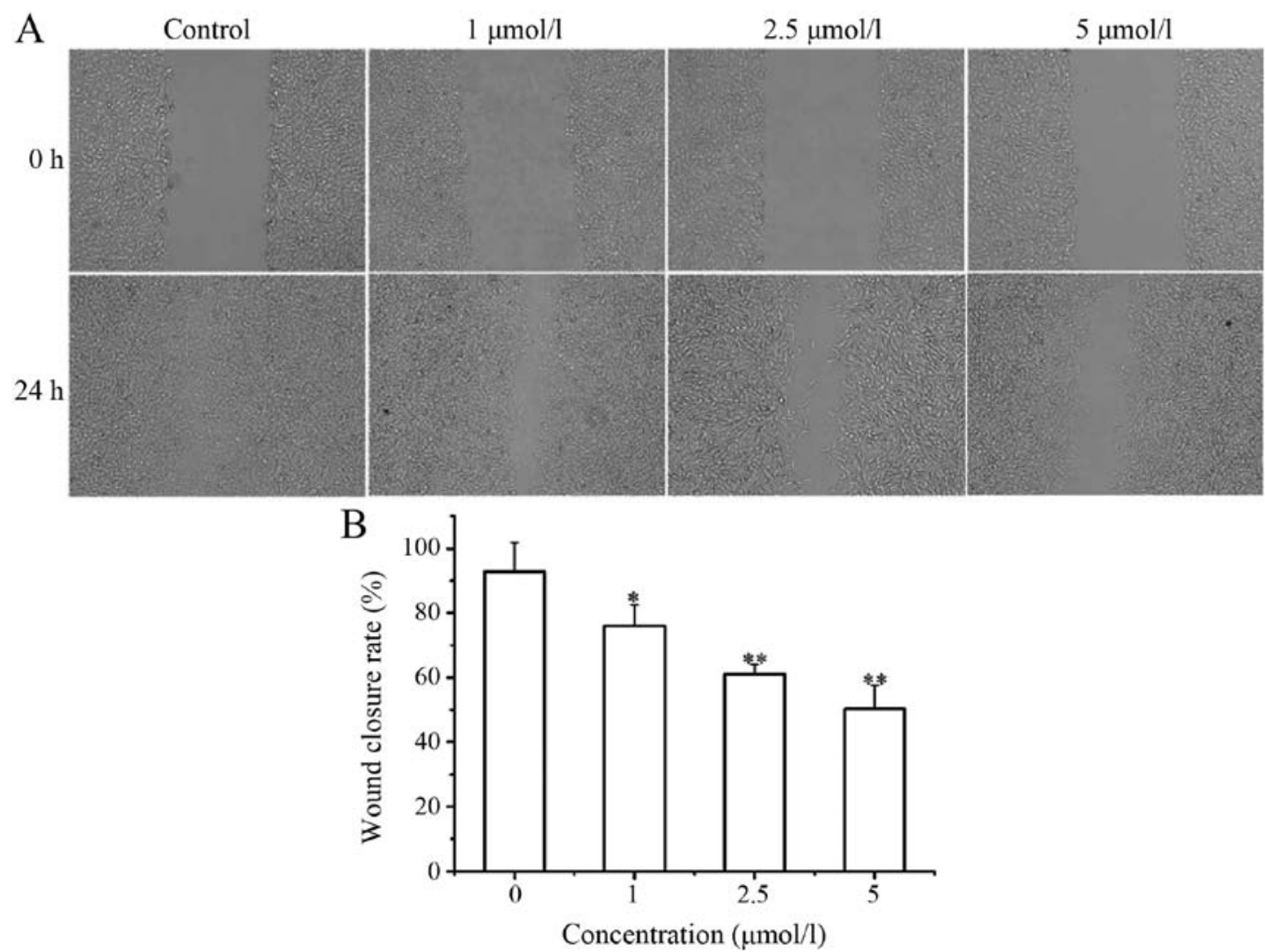

Figure 8. Licochalcone D (LD) decreases A375 cell migration at low concentrations. (A) Representative image of the wound healing ability of A375 cells treated with low concentrations of $\mathrm{LD}(1,2.5$ and $5 \mu \mathrm{mol} / \mathrm{l})$ under a x200 light microscope (Carl Zeiss). (B) Analysis of the wound closure rate of A375 cells by quantitation. All data are presented as the means $\pm \mathrm{SD}$ of at least three independent experiments; $\mathrm{P}<0.05,{ }^{* * *} \mathrm{P}<0.01$ as compared with the normal control group.

A

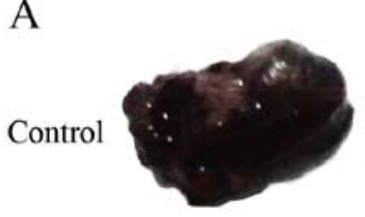

$25 \mathrm{mg} / \mathrm{kg}$

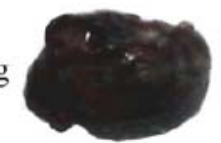

$50 \mathrm{mg} / \mathrm{kg}$

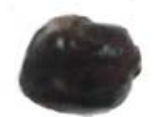

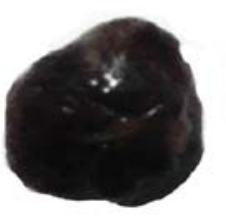

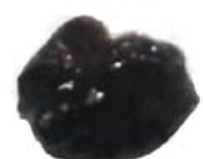

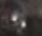
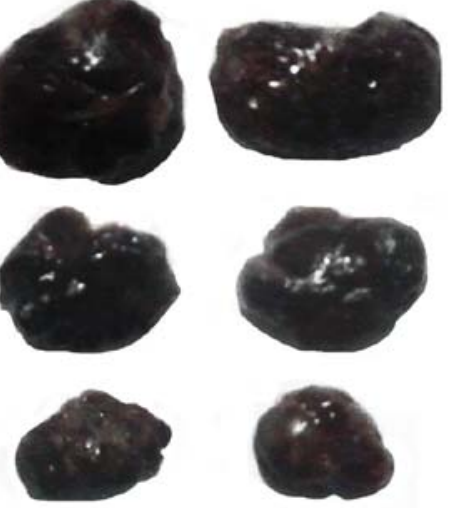

$\mathrm{B}$

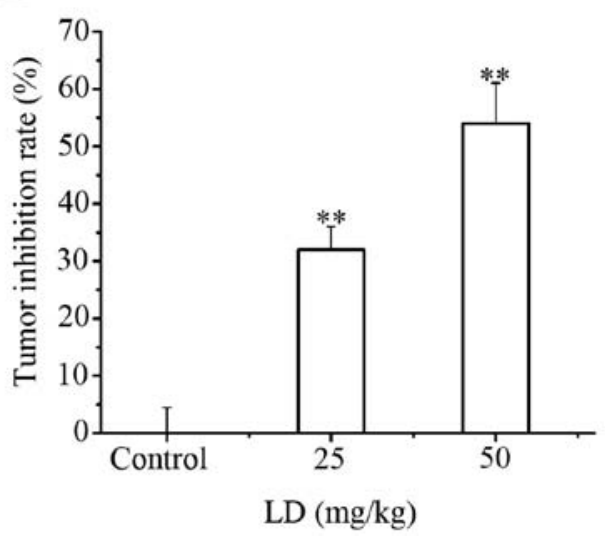

Figure 9. Licochalcone D (LD) inhibits tumor growth in a mouse xenograft model of murine melanoma B16F0 cells. (A) Representative images of the tumor morphology. (B) Data for the tumor inhibition rate of LD on tumor growth. Data are presented as means \pm SD of at least three independent experiments. ${ }^{*} \mathrm{P}<0.05,{ }^{* *} \mathrm{P}<0.01$ as compared with the untreated control group.

LD inhibits the tumor growth in a mouse xenograft model of murine melanoma B16F0 cells. Based on the findings that LD induced A375 cell apoptosis in vitro, we used B16F0 tumor models to measure whether LD could suppress tumor progression in vivo. C57BL/6 mice bearing melanoma B16F0 cell-derived tumors were used as an in vivo model to evaluate the effects of LD. Compared with the control group, the tumor growth rates were obviously lower in mice treated with LD. The tumor growth inhibition rates were calculated to be
32.0 and $54.1 \%$ in the LD-treated groups ( 25 and $50 \mathrm{mg} / \mathrm{kg}$ ), respectively (Fig. 9A and B).

\section{Discussion}

In recent decades, the incidence of malignant melanoma has rapidly increased, and it is urgent to develop new drugs to treat melanoma. In the present study, we found that Licochalcone D (LD). a flavonoid compound mainly existing in the root of 
Glycyrrhiza inflata, was a potent inhibitor of the proliferation of human melanoma cells.

Our results demonstrated that LD inhibited the proliferation of A375 cells through apoptosis induction. Apoptosis plays an important role in the development and maintenance of tissue homeostasis and the elimination of unwanted or damaged cells (18). Therefore, inducing apoptosis is a promising strategy with which to treat cancers (19). There are two classic apoptotic pathways. Firstly, caspase-3 and caspase-9 play a central role (20). Secondly, Bcl-2 family protein is involved in the induction of intrinsic apoptosis, including pro-apoptotic protein Bax and anti-apoptotic protein Bcl-2 (21). In our study, the results showed that the occurrence of apoptosis induced by LD was confirmed.

Moreover, evidence has shown that the ROS concentration plays a role in cell apoptosis or cell cycle arrest activated by anticancer agents $(22,23)$. The role of ROS in cancer biology is rather complex. A modest level of ROS is required for tumor promotion, while excessive or low levels of ROS may disrupt mitochondrial membrane potential and induce apoptosis $(24,25)$. In the present study, the mitochondrial membrane potential assay results demonstrated that LD significantly triggered dissipation of mitochondrial membrane potential $(\Delta \Psi \mathrm{m})$ of A375 cells, which suggested that the mitochondrial-mediated pathway may be involved in LD-induced apoptosis. The loss of $\Delta \Psi \mathrm{m}$ could induce the increase in intracellular ROS, which is strongly supported by the result of the ROS detection assay. Therefore, the intrinsic apoptotic pathway may be involved in the apoptotic death of A375 cells induced by LD.

The metastatic process of melanoma is complex. Tumor cell invasion and migration are key steps during tumor metastasis. Migration plays an important role in the transport of cancer cells into the blood vessels as well as the extravasation to secondary organs $(26,27)$. Therefore, it is indispensable to examine whether LD inhibits A375 cell migration and invasion. In this research, we utilized assays to confirm the anti-metastatic ability of LD by targeting tumor cell migration and invasion. We observed that treatment of metastatic A375 cells with LD markedly inhibited tumor cell migration and invasion

In addition, MMPs play a fundamental role in extracellular matrix degradation related to cancer cell invasion and metastasis. MMP-2 and MMP-9 have been reported to be most closely associated with metastatic potential. Cancer cell invasion and migration into surrounding tissues are mediated by MMP-2 and MMP-9 (28). MMP-2 and MMP-9 can degrade extracellular matrix and regulate the ability of cells to migrate. Overexpression of MMP-2 and MMP-9 promotes cancer progression and is highly correlated with poor prognosis of cancer patients (29). Targeting of MMP-2 and MMP-9 represents a promising strategy for cancer treatment (30). Therefore, regulation of MMP-2 and MMP-9 are essential for preventing cancer invasion and metastasis. In the present study, we examined the effect of LD on the secretion and expression of MMP-2 and MMP-9, and the results indicated that LD decreased MMP-2 and MMP-9 activity and expression levels. In addition, intragastric injection of LD into our mouse model of melanoma suppressed tumor growth in vivo.

Based on these observations, we propose that LD may be a potential drug for human melanoma treatment by inhibiting proliferation, inducing apoptosis via the mitochondrial pathway and blocking cell migration.

\section{Acknowledgements}

Not applicable.

\section{Funding}

This study was supported by the National Natural Science Foundation of China (nos. 31471338 and 81260338 to QZ and 81602556 to DL), the Dominant Disciplines' Talent Team DevelopmentSchemeofHigherEducation of ShandongProvince (no. 201608052410), the Scientific Research Foundation of Binzhou Medical University (no. BY2014KYQD01 to QZ) and the Innovative Team Areas of Key Areas of Xinjiang Production and Construction Corps (no. 2015BD005 to QZ).

\section{Availability of data and materials}

The datasets used during the present study are available from the corresponding author upon reasonable request.

\section{Authors' contributions}

LS and XY conceived and designed the study. LS, XY, WH, $\mathrm{XM}, \mathrm{HR}$ and BR performed the experiments. LS and XY wrote the manuscript. QZ, DL and ZD reviewed and edited the manuscript and were also involved in the conception of the study. All authors read and approved the manuscript and agree to be accountable for all aspects of the research in ensuring that the accuracy or integrity of any part of the work are appropriately investigated and resolved.

\section{Ethics approval and consent to participate}

All experimental protocols in this study were performed after approval by the Institutional Animal Care and Use Committee of Shihezi University.

\section{Consent for publication}

Not applicable.

\section{Competing interests}

The authors declare that they have no competing interests.

\section{References}

1. Franklin C, Livingstone E, Roesch A, Schilling B and Schadendorf D: Immunotherapy in melanoma: Recent advances and future directions. Eur J Surg Oncol 43: 604-611, 2017.

2. Reuland SN, Goldstein NB, Partyka KA, Cooper DA, Fujita M, Norris DA and Shellman YG: The combination of BH3-mimetic ABT-737 with the alkylating agent temozolomide induces strong synergistic killing of melanoma cells independent of p53. PLoS One 6: e24294, 2011.

3. Yuan H, Lu X, Ma Q, Li D, Xu G and Piao G: Flavonoids from Artemisia sacrorum Ledeb. and their cytotoxic activities against human cancer cell lines. Exp Ther Med 12: 1873-1878, 2016.

4. Wang P, Yuan X, Wang Y, Zhao H, Sun X and Zheng Q: Licochalcone $\mathrm{C}$ induces apoptosis via $\mathrm{B}$-cell lymphoma 2 family proteins in T24 cells. Mol Med Rep 12: 7623-7628, 2015.

5. Yang X, Jiang J, Yang X, Han J and Zheng Q: Licochalcone A induces T24 bladder cancer cell apoptosis by increasing intracellular calcium levels. Mol Med Rep 14: 911-919, 2016. 
6. Wang Y, Ma J, Yan X, Chen X, Si L, Liu Y, Han J, Hao W and Zheng Q: Isoliquiritigenin inhibits proliferation and induces apoptosis via alleviating hypoxia and reducing glycolysis in melanoma B16F10 cells. Recent Pat Anticancer Drug Discov 11: 215-227, 2016.

7. Yu L, Ma J, Han J, Wang B, Chen X, Gao C, Li D and Zheng Q: Licochalcone $\mathrm{B}$ arrests cell cycle progression and induces apoptosis in human breast cancer MCF-7 cells. Recent Pat Anticancer Drug Discov 11: 444-452, 2016.

8. Haraguchi $\mathrm{H}$, Ishikawa $\mathrm{H}$, Mizutani $\mathrm{K}$, Tamura $\mathrm{Y}$ and Kinoshita T: Antioxidative and superoxide scavenging activities of retrochalcones in Glycyrrhiza inflata. Bioorg Med Chem 6: 339-347, 1998.

9. Hong GP, Bak EJ, Woo GH, Kim JM, Quan Z, Kim JM, Yoon HK, Cheon SH, Yoon G, Yoo YJ, et al: Licochalcone E has an antidiabetic effect. J Nutr Biochem 23: 759-767, 2012.

10. Kim SJ, Kim CG, Yun SR, Kim JK and Jun JG: Synthesis of licochalcone analogues with increased anti-inflammatory activity. Bioorg Med Chem Lett 24: 181-185, 2014

11. Esmaeli A, Moshrefi M, Shamsara A, Eftekhar-Vaghefi SH and Nematollahi-Mahani SN: Xeno-free culture condition for human bone marrow and umbilical cord matrix-derived mesenchymal stem/stromal cells using human umbilical cord blood serum. Int J Reprod Biomed 14: 567-576, 2016.

12. Hung CM, Lin YC, Liu LC, Kuo SC, Ho CT and Way TD: CWF-145, a novel synthetic quinolone derivative exerts potent antimitotic activity against human prostate cancer: Rapamycin enhances antimitotic drug-induced apoptosis through the inhibition of Akt/mTOR pathway. Chem Biol Interact 260: 1-12, 2016.

13. Magro AM, Magro AD, Cunningham $C$ and Miller MR Down-regulation of vinculin upon MK886-induced apoptosis in LN18 glioblastoma cells. Neoplasma 54: 517-526, 2007.

14. Fu Q, Dai S, Zhou Y, Zheng H, Xiang H, Tian X, Gao F, Manyande A, Cao F, Tian Y and Ye D: MHC-I promotes apoptosis of GABAergic interneurons in the spinal dorsal horn and contributes to cancer induced bone pain. Exp Neurol 286: 12-20, 2016.

15. Chang HT, Chou CT, Chen IS, Yu CC, Lu T, Hsu SS, Shieh P, Jan CR and Liang WZ: Mechanisms underlying effect of the mycotoxin cytochalasin $\mathrm{B}$ on induction of cytotoxcity, modulation of cell cycle, $\mathrm{Ca}^{2+}$ homeostasis and ROS production in human breast cells. Toxicology 370: 1-19, 2016.

16. Zhou Y, Lin S, Tseng KF, Han K, Wang Y, Gan ZH, Min DL and Hu HY: Selumetinib suppresses cell proliferation, migration and trigger apoptosis, G1 arrest in triple-negative breast cancer cells. BMC Cancer 16: 818, 2016.
17. Yun J, Kim BG, Kang JS, Park SK, Lee K, Hyun DH, Kim HM, In MJ and Kim DC: Lipid-soluble ginseng extract inhibits invasion and metastasis of B16F10 melanoma cells. J Med Food 18: 102-108, 2015.

18. Malumbres M and Barbacid M: Cell cycle, CDKs and cancer: A changing paradigm. Nat Rev Cancer 9: 153-166, 2009.

19. Hunter AM, LaCasse EC and Korneluk RG: The inhibitors of apoptosis (IAPs) as cancer targets. Apoptosis 12: 1543-1568, 2007.

20. Slee EA, Adrain C and Martin SJ: Executioner caspase-3, -6, and -7 perform distinct, non-redundant roles during the demolition phase of apoptosis. J Biol Chem 276: 7320-7326, 2001.

21. Autret A and Martin SJ: Emerging role for members of the Bcl-2 family in mitochondrial morphogenesis. Mol Cell 36: 355-363, 2009.

22. Apel K and Hirt H: Reactive oxygen species: Metabolism, oxidative stress, and signal transduction. Annu Rev Plant Biol 55: 373-399, 2004.

23. Li L, Cao W, Zheng W, Fan C and Chen T: Ruthenium complexes containing 2,6-bis(benzimidazolyl)pyridine derivatives induce cancer cell apoptosis by triggering DNA damage-mediated p53 phosphorylation. Dalton Trans 41: 12766-12772, 2012.

24. Halliwell B: Oxidative stress and cancer: Have we moved forward? Biochem J 401: 1-11, 2007.

25. Wu X and Hua X: Targeting ROS: Selective killing of cancer cells by a cruciferous vegetable derived pro-oxidant compound. Cancer Biol Ther 6: 646-647, 2007.

26. Fidler IJ: The pathogenesis of cancer metastasis: The 'seed and soil' hypothesis revisited. Nat Rev Cancer 3: 453-458, 2003.

27. Nguyen DX and Massagué J: Genetic determinants of cancer metastasis. Nat Rev Genet 8: 341-352, 2007.

28. Fietz S, Einspanier R, Hoppner S, Hertsch B and Bondzio A: Determination of MMP-2 and -9 activities in synovial fluid of horses with osteoarthritic and arthritic joint diseases using gelatin zymography and immunocapture activity assays. Equine Vet J 40: 266-271, 2008

29. Liu J, Ping W, Zu Y and Sun W: Correlations of lysyl oxidase with MMP2/MMP9 expression and its prognostic value in non-small cell lung cancer. Int J Clin Exp Pathol 7: 6040-6047, 2014.

30. Jacob A and Prekeris R: The regulation of MMP targeting to invadopodia during cancer metastasis. Front Cell Dev Biol 3: 4, 2015.

This work is licensed under a Creative Commons Attribution-NonCommercial-NoDerivatives 4.0 International (CC BY-NC-ND 4.0) License. 